\title{
Ginkgo biloba Extract (GbE) Stimulates the Hypothalamic Serotonergic System and Attenuates Obesity in Ovariectomized Rats
}

\section{OPEN ACCESS}

Edited by:

Youssef Sari,

University of Toledo, United States

Reviewed by:

Lynn G. Kirby,

University of Pennsylvania,

United States

Jean-Philippe Guilloux,

Université Paris-Sud, France

*Correspondence:

Mônica M. Telles

mmtelles75@gmail.com;

mmtelles@unifesp.br

Specialty section:

This article was submitted to

Neuropharmacology,

a section of the journal

Frontiers in Pharmacology

Received: 31 January 2017

Accepted: 21 August 2017

Published: 05 September 2017

Citation:

Banin RM, de Andrade IS, Cerutti SM, Oyama LM, Telles MM and Ribeiro EB (2017) Ginkgo biloba

Extract (GbE) Stimulates the Hypothalamic Serotonergic System and Attenuates Obesity

in Ovariectomized Rats.

Front. Pharmacol. 8:605.

doi: 10.3389/fphar.2017.00605

\section{Renata M. Banin ${ }^{1,2}$, Iracema S. de Andrade ${ }^{1}$, Suzete M. Cerutti ${ }^{2}$, Lila M. Oyama ${ }^{1}$, Mônica M. Telles ${ }^{1,2 *}$ and Eliane B. Ribeiro ${ }^{1}$}

' Disciplina de Fisiologia da Nutrição, Departamento de Fisiologia, Universidade Federal de São Paulo, São Paulo, Brazil, 2 Setor de Morfofisiologia e Patologia, Departamento de Ciências Biológicas, Universidade Federal de São Paulo, Diadema, Brazil

Menopause is associated with increased risk to develop obesity but the mechanisms involved are not fully understood. We have shown that Ginkgo biloba extract (GbE) improved diet-induced obesity. Since GbE might be effective in the treatment of obesity related to menopause, avoiding the side effects of hormone replacement therapy, we investigated the effect of GbE on hypothalamic systems controlling energy homeostasis. Wistar rats were either ovariectomized (OVX) or Sham-operated. After 2 months, either $500 \mathrm{mg} \cdot \mathrm{kg}^{-1}$ of GbE or vehicle were administered daily by gavage for 14 days. A subset of animals received an intracerebroventricular (i.c.v.) injection of serotonin $(300 \mu \mathrm{g})$ or vehicle and food intake was measured after 12 and $24 \mathrm{~h}$. Another subset was submitted to in vivo microdialysis and 5-HT levels of the medial hypothalamus were measured by high performance liquid chromatography, before and up to $2 \mathrm{~h}$ after the administration of $500 \mathrm{mg} \cdot \mathrm{kg}^{-1}$ of $\mathrm{GbE}$. Additional animals were used for quantification of $5-\mathrm{HT}_{1 \mathrm{~A}}, 5-\mathrm{HT}_{1 \mathrm{~B}}, 5-\mathrm{HT}_{2 \mathrm{C}}, 5-\mathrm{HTT}$, and pro-opiomelanocortin hypothalamic protein levels by Western blotting. OVX increased food intake and body weight and adiposity while GbE attenuated these alterations. i.c.v. serotonin significantly reduced food intake in Sham, Sham $+\mathrm{GbE}$, and $\mathrm{OVX}+\mathrm{GbE}$ groups while it failed to do so in the OVX group. In the OVX rats, GbE stimulated 5-HT microdialysate levels while it reduced hypothalamic $5-\mathrm{HTT}$ protein levels. The results indicate that GbE improved the ovariectomy-induced resistance to serotonin hypophagia, at least in part through stimulation of the hypothalamic serotonergic activity. Since body weight gain is one of the most important consequences of menopause, the stimulation of the serotonergic transmission by GbE may represent a potential alternative therapy for menopause-related obesity.

\section{Keywords: ovariectomy, obesity, serotonin, hypothalamus, food intake, in vivo microdialysis, Ginkgo biloba extract}

\footnotetext{
Abbreviations: 5-HIAA, 5-hydroxyindoleacetic acid; $5-\mathrm{HT}_{1 \mathrm{~A}}$, serotonin receptor $1 \mathrm{~A} ; 5-\mathrm{HT}_{1 \mathrm{~B}}$, serotonin receptor $1 \mathrm{~B}$; $5-\mathrm{HT}_{2 \mathrm{C}}$, serotonin receptor 2C; 5 -HTT, serotonin transporter; $\alpha$-MSH, $\alpha$-melanocyte-stimulating hormone; AgRP, agoutirelated protein; AP, anteroposterior (stereotaxic coordinate); CART, cocaine- and amphetamine-regulated transcript; DV, dorsoventral (stereotaxic coordinate); ER, estrogen receptor; GbE, Ginkgo biloba (standardized) extract; GbE 761, Ginkgo biloba 761 standardized extract; HRT, hormone replacement therapy; kcal, kilocalorie; ML, mediolateral (stereotaxic coordinate); NPY, neuropeptide Y; OVX, ovariectomized; POMC, pro-opiomelanocortin; Sham, false-ovariectomized; $\mathrm{T}^{\circ} \mathrm{C}$, temperature in Celsius degrees; $\mathrm{U}$, units.
} 


\section{INTRODUCTION}

Menopause is a physiological condition characterized by the loss of ovarian function (Dalal and Agarwal, 2015). Hypoestrogenism has been identified as the main factor of menopause-associated alterations, which include obesity, decreased energy expenditure, vasomotor symptoms, insomnia, and psychological disturbances, all affecting negatively the quality of life (Al-Safi and Santoro, 2014; Jenabi et al., 2015).

Estrogens are known to play an important role in the homeostatic control of food intake and body weight (Eckel, 2011; Asarian and Geary, 2013). During the estrous phase, female rats exhibited a decrease in the size of spontaneous meals, a pattern similar to that observed in women, which presented daily food intake alterations during the hormonal fluctuations of the ovarian cycle. On the other hand, estradiol replacement attenuated ovariectomy-induced binge eating and high body weight in rats (Yu et al., 2011; Baker and Runfola, 2016).

A role of estrogens as modulators of the central serotonergic activity has been demonstrated, but with both stimulatory and inhibitory effects on the system. Indeed, they reportedly increased the expression of tryptophan hydroxylase and of serotonergic receptors and auto-receptors (Bethea et al., 2002, 2016; Hiroi and Neumaier, 2009; Barth et al., 2015).

Central serotonin (5-HT) plays a pivotal role in the control of energy homeostasis due to its anorexigenic action, exerted mainly via the receptor subtypes $5-\mathrm{HT}_{1 \mathrm{~B}}$ and $5-\mathrm{HT}_{2} \mathrm{C}$ (Huang et al., 2004). Moreover, increased 5-HT availability, as evoked by 5-HT reuptake inhibitors, induces hypophagia in both humans and animals (Huang et al., 2004; Olivier and van Oorschot, 2005). However, studies about the central activity of 5-HT in a situation of lack of ovarian hormones are very scarce.

Ginkgo biloba is one of the herbal medicines most used worldwide (Diamond and Bailey, 2013). G. biloba 761 standardized extract (GbE 761), made from its dried green leaves, is one of the best extracts related to therapeutic purposes. It has been described that G. biloba has beneficial effects on neurological disturbances, including memory loss, dementia, mood fluctuations, psychomotor symptoms, and psychiatric disorders such as schizophrenia and Alzheimer's disease (Diamond and Bailey, 2013; Montes et al., 2015). We have recently demonstrated that $\mathrm{GbE}$ administration to diet-induced obese rats led to significant decrements of food intake, body weight gain and visceral adiposity, suggesting its potential as a weight management therapy (Banin et al., 2014; Hirata et al., 2015).

There are few studies examining the effect of GbE on serotonergic pathways. In a review about its neuroprotective effects, GbE has been reported to prevent the aging-induced reductions in 5-HT levels and $5-\mathrm{HT}_{1 \mathrm{~A}}$ receptors density in the rat cerebral cortex. Furthermore, GbE 761 stimulated 5-HT uptake by cortical synaptosomes of mice, an action attributed to its flavonoid component quercetin (Ahlemeyer and Krieglstein, 2003). GbE 761 has recently been shown to inhibit reuptake transporters of norepinephrine, serotonin, and dopamine, as well as to decrease monoamine oxidase (MAO) activity (Fehske et al., 2009). Interestingly, the use of $\mathrm{GbE}$ and other herbal medicines, as alternative or complementary therapy, by postmenopausal women has been shown improve mood, hot flashes, and cognitive symptoms (Kam et al., 2002; Clement et al., 2011). However, there is no data about beneficial effects of $\mathrm{GbE}$ on the control of food intake and body weight gain related to menopause.

The present study aimed at investigating, in an ovariectomized (OVX) rat model, whether the lack of ovarian hormones affects aspects of the central serotonergic system related to energy balance and whether GbE therapy is able to modify these effects.

\section{MATERIALS AND METHODS}

\section{Animals and Ovariectomy Surgery}

All procedures were approved by the Ethics Committee on Animal Research of the Universidade Federal de São Paulo (process number: CEP 0024/13), which follows the guidelines of National Institutes of Health guide for the care and use of Laboratory animals (NIH Publications No. 8023, revised 1978). Throughout the experimental period, the female Wistar rats were maintained under controlled temperature $\left(23 \pm 1^{\circ} \mathrm{C}\right)$ and lighting conditions (lights on from 6 a.m. to 6 p.m.), with free access to water and balanced diet $\left(\right.$ Nuvilab $^{\circledR}$, Brazil,

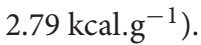

OVX $(n=49)$ or Sham $(n=48)$ were performed by the dorsal approach in 2-month-old female rats anesthetized with ketamine/xylazine $\left(66.6 / 13.3 \mathrm{mg} . \mathrm{kg}^{-1}\right.$, i.p.) and treated with an oral dose ( $25 \mathrm{mg} \cdot \mathrm{kg}^{-1}$ body weight) of ibuprofen. After the surgery, a subcutaneous dose of $300,000 \mathrm{U} \cdot \mathrm{kg}^{-1}$ body weight of penicillin $\left(1,200,000 \mathrm{U}\right.$ benzathine benzylpenicillin Bepeben $\left.{ }^{\circledR}\right)$ was administered. An analgesic reinforcement was carried out 12, 24 , and $36 \mathrm{~h}$ after the surgery. In all animals, ovariectomy was confirmed at the end of the experimental period, by the atrophy of the uteri, contrasting with the false-OVX animals.

Both body weight and daily food intake were measured once weekly for 8 weeks since the surgeries and then the phytotherapy treatment was initiated. Food efficiency was calculated by the ratio of body weight gain (g)/food ingestion (g) (de Sá et al., 2016) during the 8 -week period after ovariectomy.

\section{Phytotherapy Treatment}

GbE was obtained from Huacheng Biotech Inc. (China). The composition of $\mathrm{GbE}$ included flavone glycosides (25.21\%), terpenoids (6.62\%), ginkgolides A, B, C (3.09\%), and bilobalides $(2.73 \%)$.

Two months after ovariectomy, the Sham and OVX rats were randomly divided into four groups, treated with either vehicle or GbE: Sham $(n=24)$, Sham + GbE $(n=24)$, OVX $(n=24)$, and OVX $+\mathrm{GbE}(n=25)$. The treatment consisted of a gavage with $500 \mathrm{mg} \cdot \mathrm{kg}^{-1} \mathrm{GbE}$ diluted in $1.5 \mathrm{~mL} 0.9 \%$ saline (groups Sham $+\mathrm{GbE}$ and OVX $+\mathrm{GbE}$ ) or $1.5 \mathrm{~mL}$ of vehicle (groups Sham and OVX) and was performed once daily for 14 days. During the treatment, body weight and food intake were measured daily and cumulative food intake was calculated as the sum of the daily dietary intakes of the whole treatment period. 


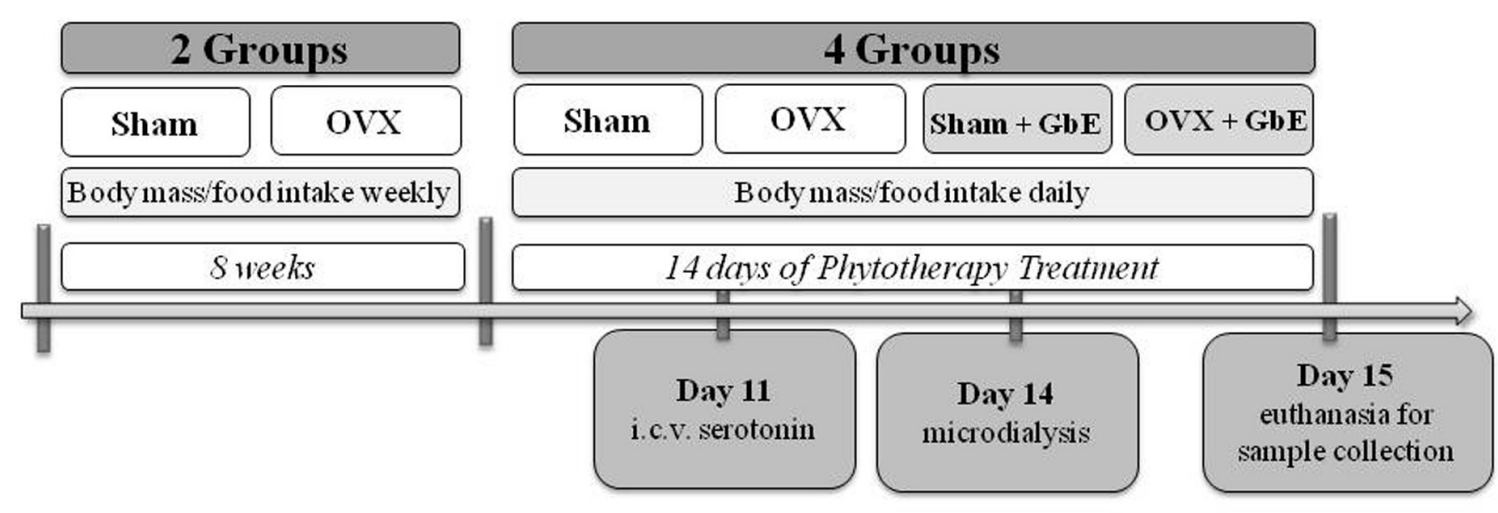

FIGURE 1 | Timeline of the experimental design.

A schematic timeline of major events involving the experimental groups is shown in Figure 1.

\section{Stereotaxic Surgery}

At the 7th day of phytotherapy treatment, the rats were anesthetized with ketamine/xylazine (66.6/13.3 mg.kg ${ }^{-1}$; i.p.) and, after the administration of an oral dose $\left(25 \mathrm{mg} \cdot \mathrm{kg}^{-1}\right.$ of body weight) of ibuprofen, they were submitted to stereotaxic surgery. For the intracerebroventricular (i.c.v.) serotonin injection, a subset of animals received a 21 gauge cannula (15 mm length) aimed at the left lateral ventricle [from bregma: anteroposterior $(\mathrm{AP})=-0.9 \mathrm{~mm}$; mediolateral $(\mathrm{ML})=+1.6 \mathrm{~mm}$; dorsoventral $(\mathrm{DV})=-2.5 \mathrm{~mm}$ ]. For the microdialysis study, a subset of animal received a 20 gauge cannula (20 mm length) aimed at the right ventromedial hypothalamus (from bregma: $\mathrm{AP}=-2.6 \mathrm{~mm}$; $\mathrm{ML}=-0.6 \mathrm{~mm}$; DV $=-7.8 \mathrm{~mm}$ ). The cannulas were secured to the skull with screws and dental cement. Immediately after the surgery, a subcutaneous dose of penicillin $\left(300,000 \mathrm{U} \cdot \mathrm{kg}^{-1}\right.$, Bepeben ${ }^{\circledR}$ ) was administered. The rats were then placed in individual cages with free access to water and food and continued to receive the GbE treatment for the following 7 days. Food intake and body weight were measured daily to check for the post-surgical recovery.

\section{Food Intake Measurement after Intracerebroventricular Serotonin}

After 3 days of the lateral ventricle cannulation, the animals were fasted for $6 \mathrm{~h}$ and received an i.c.v. injection of $5.0 \mu \mathrm{L}$ of vehicle (artificial cerebrospinal fluid: $145 \mathrm{mM} \mathrm{NaCl}, 2.7 \mathrm{mM} \mathrm{KCl} ; 1.0 \mathrm{mM}$ $\left.\mathrm{MgCl}_{2} ; 1.2 \mathrm{mM} \mathrm{CaCl} 2 ; 2.0 \mathrm{mM} \mathrm{Na} \mathrm{HPO}_{4} ; \mathrm{pH} 7.4\right)$ or $5.0 \mu \mathrm{L}$ of vehicle containing $300 \mu \mathrm{g}$ of 5-HT (H9523, Sigma-Aldrich, United States). The injections were performed immediately before lights out. After the injection, the animals were returned to their individual cages and a known amount of chow was offered. Food consumption was determined by weighting the remaining chow after 12 and $24 \mathrm{~h}$ of the injection. Each animal was injected twice, receiving vehicle or serotonin, on separate days, with an interval of 2 days between the experiments. The rats were randomly divided, so that half of the animals received vehicle as first injection and the other half received serotonin as first injection. The correct cannula positioning was evaluated by the dipsogenic effect of $20 \mathrm{ng}$ of angiotensin II (i.c.v.).

\section{In Vivo Microdialysis}

On the 13th day of the phytotherapy treatment, around 5 p.m., food was removed and the microdialysis probe was inserted into the guide cannula. The probes were custom-constructed, as previously described, with $2.0 \mathrm{~mm}$ of effective membrane length and 13,000 Da cut-off (Mori et al., 1999; Pôrto et al., 2009). The probe inlet was connected to a micro-infusion pump (CMA-Harvard Apparatus, Kista, Stockholm, Sweden) and the animals were connected to a swivel system (CMA Microdialysis ${ }^{\circledR}$ ) allowing continuous perfusion with artificial cerebrospinal fluid. Overnight infusion flow rate was $1.0 \mu \mathrm{L} . \mathrm{min}^{-1}$. In the next day, around 8 a.m., flow rate was adjusted to $2.5 \mu \mathrm{L} \cdot \mathrm{min}^{-1}$. After allowing $60 \mathrm{~min}$ for stabilization, collection of 20-min dialysate samples was started. Samples were collected into $10 \mu \mathrm{L}$ of $0.5 \mathrm{M}$ perchloric acid and immediately injected into a high performance liquid chromatography (HPLC) system (Mori et al., 1999; Telles et al., 2003). All dialysate collections were performed between 9 and 12 a.m. Baseline samples were collected until 5-HT levels were stable. Then, the Sham + GbE and the OVX + GbE animals received $500 \mathrm{mg} \cdot \mathrm{kg}^{-1}$ of GbE by gavage while the Sham and OVX groups received $1.5 \mathrm{~mL}$ of vehicle. After the gavage procedure, six additional 20-min. microdialysate samples were collected.

\section{HPLC Analysis}

Dialysate levels of 5-HT were measured by HPLC with electrochemical detection. The system (ESA, Inc., Chelmsford, United States) consisted of a pump with two PEEK pulse dampers in series, a $50 \mu \mathrm{L}$ Rheodyne PEEK sample loop, a $3 \mu \mathrm{M}$ MD150 C18 reverse phase column, a model 5020 guard cell with $300 \mathrm{mV}$ potential, a model $5014 \mathrm{~A}$ analytical cell set a -175 and $150 \mathrm{mV}$ in the first and second electrodes, respectively, and a model $5200 \mathrm{~A}$ detector. The mobile phase consisted of $75 \mathrm{mM}$ sodium phosphate, $1.5 \mathrm{mM}$ octanesulfonic acid, $50 \mu \mathrm{M}$ EDTA, $150 \mu \mathrm{L}$ triethylamine. $\mathrm{L}^{-1}, 20 \%$ acetonitrile, $\mathrm{pH} 3.0$ at a flow rate of 0.6 mL.min ${ }^{-1}$ (Mori et al., 1999; Guimarães et al., 2002; Telles et al., 2003). 


\section{Histological Analysis and Weighing of Visceral Adipose Tissue Depots}

One day after the microdialysis experiment, the rats were deeply anesthetized with thiopental $\left(80 \mathrm{mg} \cdot \mathrm{kg}^{-1}\right.$; i.p.), the abdominal cavity was opened and the retroperitoneal and mesenteric fat pads were removed and weighed. The animals were then perfused intracardially with PBS solution followed by $4 \%$ paraformaldehyde dissolved in PBS. Brains were removed and kept in $4 \%$ paraformaldehyde for 1 week and then in 30\% sucrose solution for 4 days. The $45 \mu \mathrm{M}$ sections were obtained in a cryostat, stained with cresyl violet and examined under an optical microscope for confirmation of the positioning of the microdialysis membranes in the ventromedial hypothalamus region. We considered only the results obtained in those animals in which the microdialysis membrane was correctly positioned.

\section{Western Blotting Analysis}

Additional rats were killed after an $8 \mathrm{~h}$-fasting. The hypothalami were removed and homogenized in $0.8 \mathrm{~mL}$ of solubilization buffer $\left(100 \mathrm{mM}\right.$ Tris, $\mathrm{pH}$ 7.5, $0.1 \mathrm{mg} \cdot \mathrm{mL}^{-1}$ aprotinin, $2 \mathrm{mM}$ phenylmethylsulfonyl fluoride, $10 \mathrm{mM}$ sodium orthovanadate, $100 \mathrm{mM}$ sodium fluoride, $10 \mathrm{mM}$ sodium pyrophosphate, and $10 \mathrm{mM}$ EDTA). Triton X-100 was added to a final concentration of $10 \%$. Samples were centrifuged at $16,000 \mathrm{~g}$ for $40 \mathrm{~min}$ and $50 \mu \mathrm{g}$ of protein were resolved in SDS-polyacrylamide gel electrophoresis, transferred to nitrocellulose membranes and incubated with primary antibodies against the serotonergic receptors $5-\mathrm{HT}_{1 \mathrm{~A}}$ (anti-5$\mathrm{HT}_{1 \mathrm{~A}}, \mathrm{ab} 79230$ ), 5- $\mathrm{HT}_{1 \mathrm{~B}}$ (anti-5- $\mathrm{HT}_{1 \mathrm{~B}}, \mathrm{ab} 13896$ ), and 5- $\mathrm{HT}_{2 \mathrm{C}}$ (anti-5- $\mathrm{HT}_{2 \mathrm{C}}, \mathrm{ab} 133570$ ), the serotonin transporter-5-HTT (anti-5-HTT, ab172884), and the anorexigenic mediator proopiomelanocortin (POMC; anti-POMC, ab180766). The blots were incubated with peroxidase-conjugated secondary antibodies and specific bands were detected by chemiluminescence (GE Healthcare Bio-Sciences, Pittsburgh, PA, United States).

For evaluation of protein loading, all membranes were stripped and re-blotted with anti- $\beta$-tubulin (Ab\#2146) primary antibody. Band intensities were quantified by optical densitometry (Scion Image software, Scion Corporation, Frederick, MD, United States). The measured density of all proteins where then corrected to the density of $\beta$-tubulin levels. The results are expressed as percentage of the intensity measured in the Sham group. The whole pictures of Western blotting analysis are provided in the Supplementary Data Sheet 1.

\section{Statistical Analysis}

Data are expressed as mean \pm SEM. The PASW Statistics version 21 software (SPSS Inc., United States) was adopted in all analysis with the level of statistical significance set at $p \leq 0.05$.

Comparisons of body mass and relative food intake within Sham and OVX groups were performed by one-way ANOVA with repeated measures. Comparisons of body mass, food intake, body weight gain, and food efficiency between Sham and GbE groups were carried out by Student's $t$-test for independent samples. Comparisons of body weight gain, relative food intake, visceral adipose tissues depots, and uterus mass among all groups were analyzed by two-way ANOVA followed by Tukey HSD test adopting OVX and GbE as the fixed factors. The effect of acute i.c.v. 5-HT on food intake in each group was assessed by the paired Student's $t$-test.

5-HT microdialysate levels are expressed as percentage of the mean baseline level. For comparisons among the samples collected throughout the experimental period in the same group, one-way ANOVA followed by Tukey HSD test was performed. The area under the curve (AUC) relating serotonin levels to time after GbE or vehicle administration was calculated by the trapezoidal rule. The comparisons of microdialysate 5-HT levels among the four groups in each time point, serotonin AUC, and Western blotting data were analyzed by two-way ANOVA followed by Tukey HSD test considering OVX and GbE as main factors. Detailed tables of statistical analysis are available in the Supplementary Data Sheet 2.

\section{RESULTS}

\section{Body Weight and Food Intake during the 8 Weeks after Ovariectomy}

Both Sham $\left[F_{(1,47)}=3928.55 ; p<0.0001\right]$ and OVX $\left[F_{(1,48)}=7808.63 ; p<0.0001\right]$ rats showed a progressive elevation of their body masses, from week 0 (initial body mass) to the end of week 8, as it can be observed in Figure 2A. In comparison to the Sham group, the OVX rats presented significantly higher body mass from the 2 nd to the 8 th week after ovariectomy (week 2: $11 \%$; week 3: $17 \%$; weeks 4 and 5: $19 \%$; week 6: $20 \%$; week $7: 21 \%$; and week $8: 22 \%, p<0.0001$ ). The total body mass gain of the OVX group was $107 \%$ higher than that of the Sham group $(p<0.0001)$, as it can be verified in Figure 2B.

Figure $2 \mathrm{C}$ shows that the Sham rats exhibited a significant reduction of the relative food intake at the 4 th $(p=0.015)$, 6th $(p=0.002)$, 7 th $(p=0.001)$, and 8 th weeks $(p<0.0001)$, in relation to the 1st week of evaluation $\left[F_{(1,10)}=1577.10\right.$; $p<0.0001]$. In the OVX group, the relative food intake decreased significantly $\left[F_{(1,8)}=4712.82 ; p<0.0001\right]$ since the 2 nd week (week 2: $-7 \%, p=0.044$; week 3: $-17 \%, p=0.001$; week $4:-28 \%$, $p<0.0001$; week 5: $-29 \%, p<0.0001$; week 6: $-34 \%, p<0.0001$; week 7: $-36 \%, p<0.0001$; and week 8: $-34 \%, p<0.0001$ ). In comparison to the Sham rats, the OVX group presented a significantly higher food intake at the 1 st $(14 \%, p=0.006)$ and 2 nd weeks $(9 \%, p=0.022)$. However, this group presented a significant reduction in food intake in the 7th week in relation to Sham group $(-10 \%, p=0.009)$. By the end of the 8th week, food intake was similar between the groups. In addition, Figure 2D shows that the OVX group presented a 160\% increase of food efficiency $(p<0.0001)$ in comparison to the Sham group.

\section{Body and Adipose Tissue Mass and Food Intake in Response to 14 Days of GbE Treatment}

Body mass gain during the 14 days of $\mathrm{GbE}$ treatment failed to show significant differences among the groups $\left[F_{(3,51)}=0.506\right.$, 

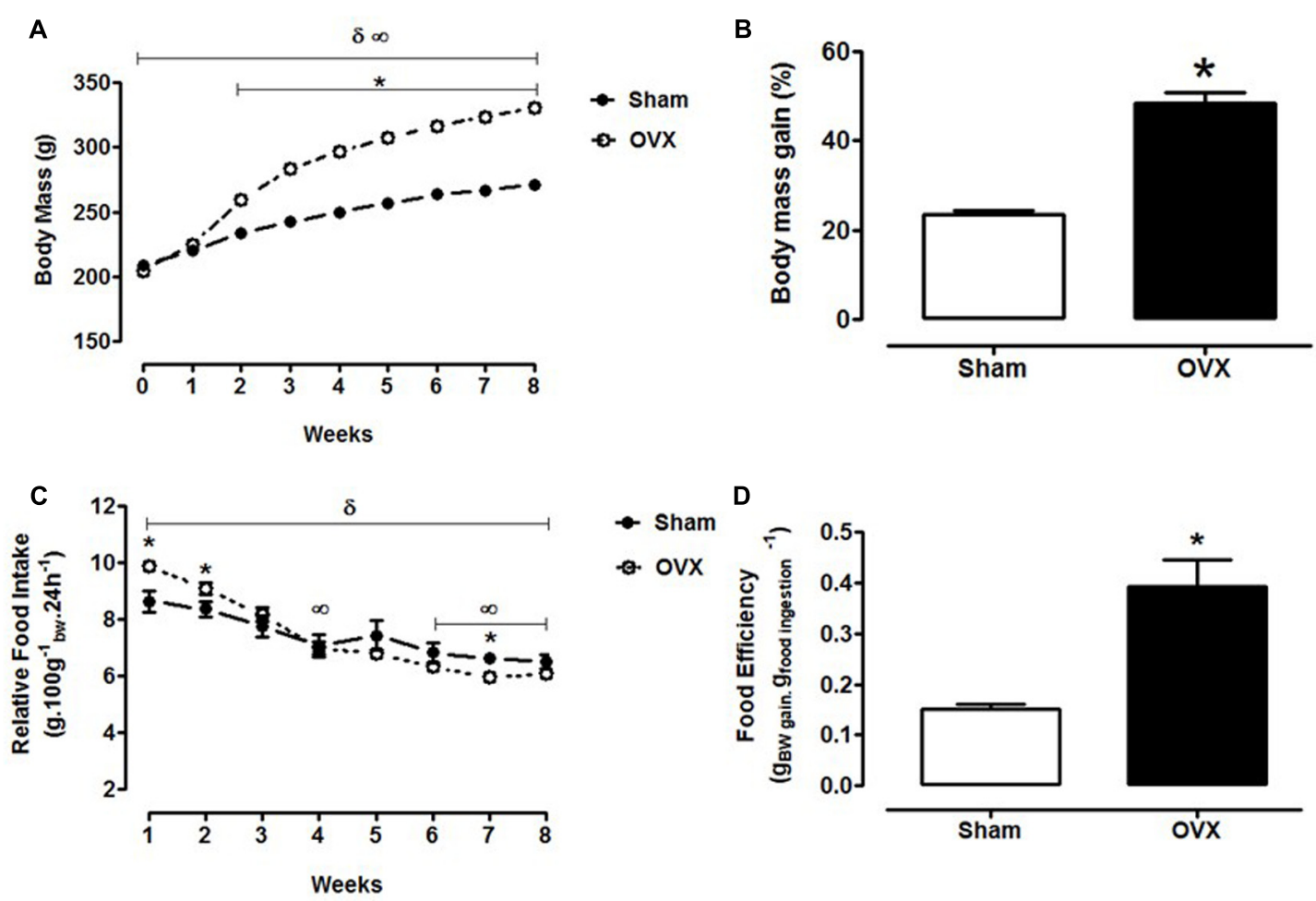

FIGURE 2 | Body mass and food intake during the 8 weeks after ovariectomy or false-ovariectomy. (A) Body mass; (B) body mass gain (\% of initial body mass); (C) relative food intake (g.100 g ${ }^{-1}$ bw. $\left.24 \mathrm{~h}^{-1}\right)$; and (D) food efficiency (g.kcal $\left.{ }^{-1}\right)$ of Sham $(n=48)$ and OVX rats $(n=49) .{ }^{\infty} p \leq 0.05$ vs. week 0 within the Sham group; ${ }^{\delta} p \leq 0.05$ vs. week 0 within the OVX group; ${ }^{*} p \leq 0.05$ vs. Sham.

$p=0.680$, Figure 3A]. Ovariectomy increased the mass of the retroperitoneal $\left[F_{(3,79)}=45.66, p<0.0001\right]$ and the mesenteric $\left[F_{(3,79)}=49.44, p<0.0001\right]$ fat depots and of the sum of these visceral fat depots $\left[F_{(3,79)}=54.96, p<0.0001\right]$, in comparison to Sham and the Sham + GbE groups. GbE attenuated these adiposity measures, as the OVX + GbE rats showed a $23 \%$ reduction $(p=0.027)$ of retroperitoneal fat pad mass $\left[F_{(3,79)}=7.47, p=0.008\right]$ and a $20 \%$ reduction $(p=0.035)$ of visceral fat pads sum $\left[F_{(3,79)}=54.96, p<0.0001\right]$, in relation to the OVX rats (Figure 3B).

The cumulative food intake $\left[F_{(3,22)}=12.30, p=0.003\right]$ was lower in OVX + GbE than in Sham $(-15 \%, p=0.019)$ and Sham $+\mathrm{GbE}(-14 \%, p=0.023)$ groups (Figure 3C). As expected, the lack of ovarian hormones promoted a significant atrophy of the uteri $\left[F_{(3,95)}=584.46 ; p<0.0001\right]$, as compared to both Sham and Sham + GbE groups (Figure 3D).

\section{Food Intake in Response to Intracerebroventricular Serotonin}

Serotonin infusion significantly reduced food intake in relation to vehicle infusion in the Sham $(-42 \%, p=0.0017$ and $-25 \%$, $p=0.0010$; Figure 4A) and Sham $+\mathrm{GbE}(-14 \%, p=0.024$ and $-15 \%, p=0.040$; Figure 4B) groups. Serotonin-induced hypophagia was abolished in the OVX group (Figure 4C) and was restored by the $\mathrm{GbE}$ treatment $(-39 \%, p=0.047$ and $-42 \%$, $p=0.037$; Figure 4D).

\section{Effect of GbE on Serotonin Levels in Microdialysates of the Medial Hypothalamus}

Basal extracellular levels of serotonin were similar among Sham (1.05 \pm 0.22 pg.50 $\left.\mu \mathrm{L}^{-1}, \quad n=6-7\right)$, Sham + GbE (1.84 \pm 0.35 pg.50 $\left.\mu^{-1}, n=5-6\right)$, OVX $\left(1.40 \pm 0.38\right.$ pg. $\left.50 \mu \mathrm{L}^{-1}, n=5-10\right)$ and OVX $+\mathrm{GbE}$ $\left(1.11 \pm 0.20\right.$ pg. $\left.50 \mu \mathrm{L}^{-1}, n=7-10\right) ;\left[F_{(3,30)}=1.172, p=0.339\right]$ groups.

The gavage with vehicle failed to significantly affect 5-HT extracellular levels in both the Sham $\left[F_{(8,58)}=2.427, p=0.072\right]$ and the OVX groups $\left[F_{(8,68)}=0.7189, p=0.674\right]$. The injection of $\mathrm{GbE}$ failed to significantly alter 5-HT microdialysate levels in the Sham + GbE group $\left[F_{(8,52)}=0.7869, p=0.617\right]$. On the other hand, it caused a significant elevation of 5-HT levels in the OVX + GbE group $\left[F_{(8,77)}=2.675, p=0.013\right]$. The levels were significantly elevated from baseline at the sample collected 60-80 min after the acute dose of GbE (Figure 5A).

The comparison among the groups at each time point showed that GbE promoted a significant increment of 5-HT levels $\left[F_{(3,29)}=9.255, p=0.005\right]$ in both Sham $+\mathrm{GbE}$ and OVX + GbE rats, in the 20-40 min sample $(67 \%, p=0.042 ; 64 \%$, $p=0.033$, respectively) in comparison to the OVX group. GbE also increased 5-HT level of the OVX + GbE group in relation to 

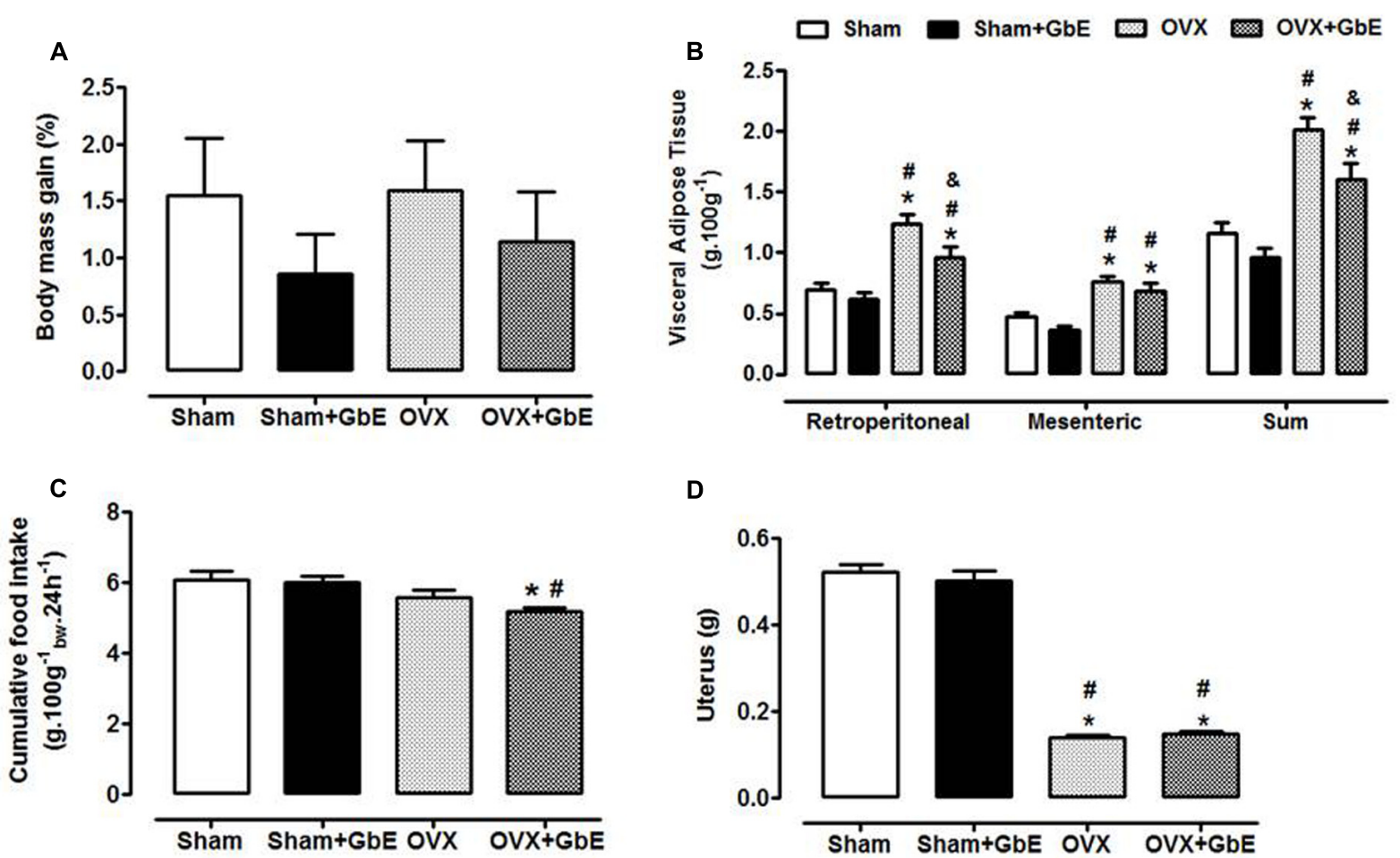

FIGURE 3 | Body mass gain and cumulative food intake during the 14 days of GbE therapy, and final fat depots and uterus mass. (A) Body mass gain (\% of initial body mass) of Sham ( $n=13)$, Sham $+\operatorname{GbE}(n=12)$, OVX $(n=14)$, and OVX $+\mathrm{GbE}(n=11)$ groups; (B) visceral adipose tissue depots mass (g.100 g $\left.\mathrm{g}^{-1}\right)$ of Sham $(n=21-24)$, Sham $+\operatorname{GbE}(n=21-23), \operatorname{OVX}(n=18-25)$, and OVX + GbE ( $n=18-23)$ groups; (C) cumulative food intake (g.100 g $\left.\mathrm{g}^{-1} \mathrm{bw}^{24} \mathrm{~h}^{-1}\right)$ of Sham ( $\left.n=13\right)$, Sham + GbE $(n=12)$, OVX ( $n=14)$, and OVX + GbE $(n=11)$ groups; (D) uterus mass (g) Sham $(n=21-24)$, Sham + GbE $(n=21-23)$, OVX $(n=18-25)$, and OVX $+\operatorname{GbE}(n=18-23)$ groups. * $p \leq 0.05$ vs. Sham; ${ }^{*} p \leq 0.05$ vs. Sham + GbE; ${ }^{*} p \leq 0.05$ vs. OVX.

that of the Sham group at the $80-100$ min sample $[67 \%, p=0.029$; $F_{(3,27)}=5.292, p=0.031$; Figure 5A]

The AUC relating serotonin levels to time after $\mathrm{GbE}$ administration was higher in OVX $+\mathrm{GbE}$ group $\left[F_{(3,31)}=6.425\right.$, $p=0.017]$ in comparison to the Sham $(47 \%, p=0.046)$ and the OVX group (45\%, $p=0.040$ ) (Figure 5B).

\section{Effects of Ovariectomy and GbE on Hypothalamic Protein Expression}

No differences were observed among the groups in protein levels of $5-\mathrm{HT}_{1 \mathrm{~A}}\left[F_{(3,48)}=0.928, p=0.435\right], 5-\mathrm{HT}_{1 \mathrm{~B}}\left[F_{(3,49)}=0.589\right.$, $p=0.625], 5-\mathrm{HT}_{2 \mathrm{C}}\left[F_{(3,49)}=0.865, p=0.465\right]$, and POMC $\left[F_{(3,45)}=0.371, p=0.774\right]$ (Figures 6A-D). However, there was a significant $60 \%$ reduction $(p=0.043)$ in the protein levels of the 5-HTT (Figure 6E) $\left[F_{(3,45)}=3.321, p=0.029\right]$ of OVX $+\mathrm{GbE}$ rats in relation to that of the Sham group. Additionally, that group also showed a trend to elevated levels in relation to the Sham $+\operatorname{GbE}(p=0.054)$ and $\operatorname{OVX}(p=0.075)$ groups.

\section{DISCUSSION}

It is well recognized that menopause is associated with excess body mass gain and visceral fat deposition (MacLean et al., 2010; Asarian and Geary, 2013; Dalal and Agarwal, 2015). In the present study, ovariectomy induced increased body mass since the 2nd week, leading to a twofold total increase by the 8 th week. By this time, visceral adipose depots were augmented, a condition known to be linked with the development of chronic diseases such as insulin resistance, diabetes, cardiovascular disorders, and cancer (Stachowiak et al., 2015).

The daily food intake of the OVX rats showed a transient increase, in the 1 st and 2 nd weeks, but was normalized by the 8th week. This pattern of feeding agrees with a previous report in OVX rats (Ferreira et al., 2012) and may be attributed to a compensatory mechanism to control energy balance after a period of hyperphagia (Woods, 2013). However, it is important to emphasize that, although both the Sham and the OVX rats exhibited a progressive decrease of food intake over the 8 weeks, the decrement was more pronounced in the OVX group, showing that the excess weight gain did not rely on excess energy consumption. This can be explained, at least in part, by the increased food efficiency shown by the OVX rats, in accordance with a previous report on the consequences of the absence of ovarian hormones (MacLean et al., 2010).

Estrogen replacement has been shown to attenuate obesity in both OVX animals (Yu et al., 2011; Ibrahim et al., 2015) and in post-menopausal women (Butera, 2010). Estrogens regulate food intake by reducing the activity of orexigenic factors, such as ghrelin and neuropeptide Y (NPY), as well as by stimulating 


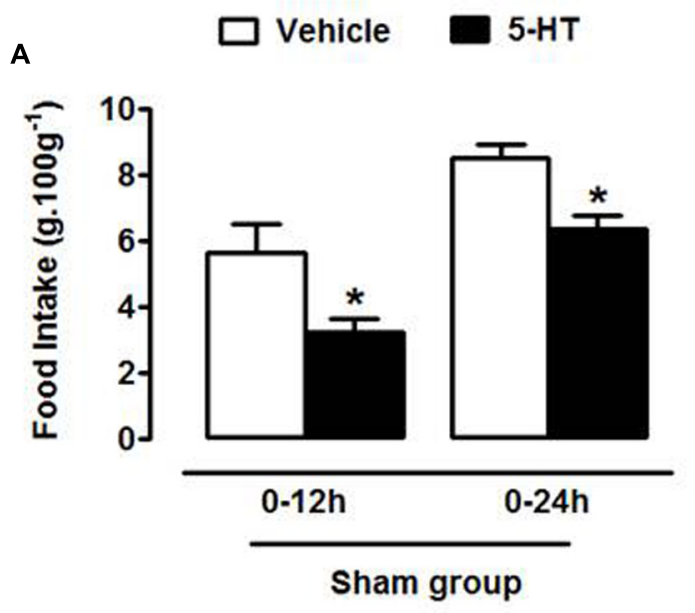

B
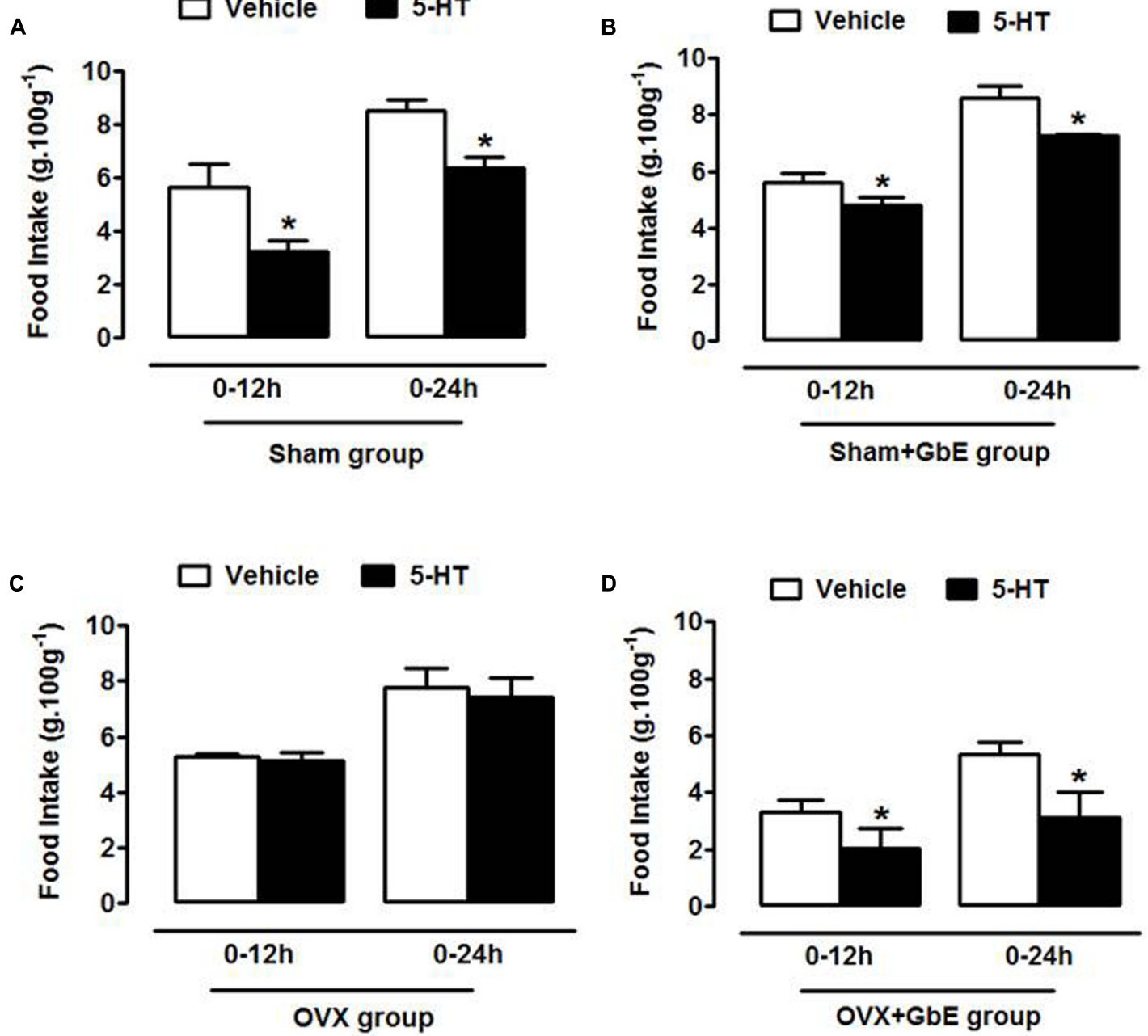

FIGURE 4 | Food intake in response to intracerebroventricular serotonin. Relative food intake of (A) Sham $(n=4)$, (B) Sham $+\operatorname{GbE}(n=4)$, (C) OVX ( $n=4)$, and (D) OVX $+\mathrm{GbE}(n=5)$ in the 12 and $24 \mathrm{~h}$ periods after the intracerebroventricular injection of either vehicle or $300 \mathrm{mg} 5-\mathrm{HT}$. * $p \leq 0.05 \mathrm{vs}$. vehicle.

anorexigenic signals, such as cholecystokinin, brain-derived neurotrophic factor and the serotonin pathway (Bethea et al., 2002, 2016; Butera, 2010; Zhu et al., 2013; Grochans et al., 2014).

Hormone replacement therapy (HRT) remains the most used treatment for ameliorating menopause-related symptoms, as it presents positive effects on food intake control and body weight gain. Nevertheless, as HRT may lead to important side effects such as breast cancer, heart stroke, and thrombosis, this therapy must be well evaluated and constantly monitored (Pines and Shapiro, 2015). In this context, the development of alternative treatments for menopause management is highly desirable.

Previous studies from our laboratory have demonstrated that GbE was efficient in reducing food intake, body weight gain, and visceral adiposity in diet-induced obese male rats (Banin et al., 2014; Hirata et al., 2015). Due to this positive effect of GbE on energy homeostasis, the present study was aimed at evaluating if this herbal medicine would attenuate the effects of ovarian hormones absence on energy homeostasis and, if so, whether the hypothalamic serotonin system played a role. The results showed that GbE did reduce spontaneous feeding and attenuated body adiposity of OVX rats during the 2-week treatment. Although few studies have addressed the mechanisms involved in GbE-induced hypophagia, a positive effect of $\mathrm{GbE}$ on components of serotonergic signaling pathway has been documented (Huguet et al., 1994; Bolaños-Jiménez et al., 1995; Sloley et al., 2000).

Since exogenous 5-HT and agents that enhance synaptic availability of endogenous 5-HT are known to suppress feeding (Leibowitz and Alexander, 1998), in the present work food intake was assessed after an i.c.v. injection of 5-HT. The results demonstrated that OVX rats failed to show hypophagia in response to an acute central infusion of serotonin. This finding agrees with the demonstration of impairment of fenfluramineinduced hypophagia in OVX rats in comparison to estradiolreplaced OVX animals (Rivera and Eckel, 2005). It has been previously reported that fluoxetine decreased appetite and body 

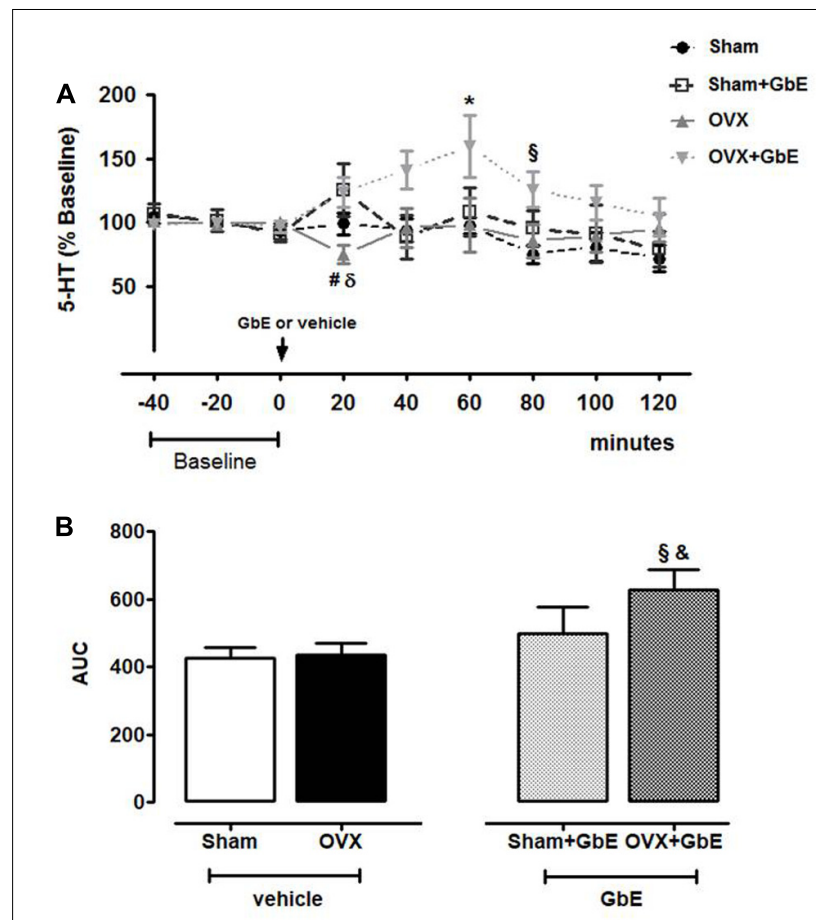

FIGURE $\mathbf{5}$ | Medial hypothalamic serotonin extracellular levels as measured by in vivo microdialysis. (A) 5-HT levels (\% baseline) in 20-min VMH microdialysate samples collected before (baseline -40 to $0 \mathrm{~min}$ ) and up to $120 \mathrm{~min}$ after gavage with either vehicle or $500 \mathrm{mg} \cdot \mathrm{kg}^{-1}$ of $\mathrm{GbE}$ and (B) area under the curve (AUC) of 5-HT extracellular levels during the 120 min of microdialysate collection after gavage of Sham $(n=6-7)$, Sham + GbE $(n=5-6), \mathrm{OVX}(n=5-10)$, and $\mathrm{OVX}+\mathrm{GbE}(n=7-10) .{ }^{*} p \leq 0.05 \mathrm{vs}$. baseline; ${ }^{\S} p \leq 0.05$ vs. Sham; ${ }^{\#} p \leq 0.05$ vs. Sham + GbE; ${ }^{*} p<0.05$ vs. OVX; ${ }^{\delta} p \leq 0.05$ vs. OVX + GbE.

mass index of post-menopausal women after 2-3 months of treatment but these effects were no longer observed after 6 months of therapy (Chojnacki et al., 2015).

Importantly, GbE improved serotonin effectiveness in the OVX animals, as seen by the restored feeding response to the neurotransmitter in the OVX $+\mathrm{GbE}$ group. Along with the observation of the low food intake presented by OVX $+\mathrm{GbE}$ rats during the 14-day treatment, this finding allows the suggestion that GbE-induced hypophagia relied, at least in part, on serotonergic mechanisms.

Indeed, the microdialysis experiments evidenced a potent effect of GbE on the serotonergic system of the OVX rats, as the treatment significantly stimulated 5-HT microdialysate levels. This agrees with the demonstration that GbE 761 increased 5-HT uptake by mice cortical synaptosomes, an effect attributed to the flavonoid compounds of GbE (Ramassamy et al., 1992). On the other hand, it contrasts with the observation of a previous report in which the authors did not observe any effect of GbE on the pre-frontal cortex extracellular 5-HT levels of rats (Yoshitake et al., 2010).

Serotonin hypophagia has been attributed to its interaction with receptors 5- $\mathrm{HT}_{1 \mathrm{~A}}, 5-\mathrm{HT}_{1 \mathrm{~B}}$, and 5- $\mathrm{HT}_{2 \mathrm{C}}$ (Huang et al., 2004). Pretreatment with $5-\mathrm{HT}_{1 \mathrm{~A}}$ antagonists impaired the hypophagia induced by fluoxetine administration in the pre-limbic cortex of fasted rats (Stanquini et al., 2015). Acting on $5-\mathrm{HT}_{2} \mathrm{C}$ receptors, 5 -HT has been shown to induce the cleavage of POMC into the active anorexigenic factor $\alpha$-melanocyte-stimulating hormone $(\alpha-\mathrm{MSH})$. Acting on $5-\mathrm{HT}_{1 \mathrm{~B}}$, serotonin reportedly inhibited the orexigenic mediators NPY and agouti-related protein (AgRP) and activated the anorexigenic peptides $\alpha-\mathrm{MSH}$ and cocaine- and amphetamine-regulated transcript (CART) (Pratt et al., 2016). Inhibition of the 5-HTT decreased food intake and body weight in rats and humans (Huang et al., 2004; Olivier and van Oorschot, 2005).

Available data addressing effects of GbE in the modulation of serotonergic receptors involved in energy homeostasis are very scarce. In the rat brain, GbE has been shown to prevent the stress-induced $5-\mathrm{HT}_{1 \mathrm{~A}}$ desensitization in the hippocampus and to reverse the aging-induced decrement of cortical 5- $\mathrm{HT}_{1 \mathrm{~A}}$ density (Huguet et al., 1994; Bolaños-Jiménez et al., 1995). A neuroprotective ability of GbE has been proposed based both on the ability of the phytoestrogen kaempferol, isolated from $\mathrm{GbE}$ leaves, to reduce MAO-A/B activity in rat brain cells in culture, and on its antioxidant effect in a lipid-peroxidation assay (Sloley et al., 2000). A better understanding of the central targets of GbE is relevant for the proposal of beneficial effects of this herbal medicine on body weight gain, particularly after menopause.

In the present study, GbE failed to affect hypothalamic levels of $5-\mathrm{HT}_{1 \mathrm{~A}}, 5-\mathrm{HT}_{1 \mathrm{~B}}, 5-\mathrm{HT}_{2} \mathrm{C}$, and POMC. On the other hand, it induced a $60 \%$ significant decrement of hypothalamic 5 -HTT density, only in the OVX rats. It is, thus, possible to suggest that $\mathrm{GbE}$ increased serotonin effectiveness through reuptake inhibition, what was probably relevant for the reduction of food intake and stimulation of 5-HT microdialysate levels induced by GbE. Differently from its action on the OVX rats, GbE had no effect on the hypothalamic 5-HTT levels in the Sham-OVX group, a finding consistent with its lack of effect on feeding and microdialysate serotonin levels in this group.

As mentioned above, estrogens' effects on the serotonergic system are complex. Although the majority of the studies have pointed to an overall stimulatory effect of estrogens, inhibitory consequences have also been described (Barth et al., 2015). Low estrogen levels have been associated with reduced 5-HT concentration in some brain areas, such as cortex and striatum (Hao et al., 2011). Furthermore, OVX rats reportedly presented a marked reduction in the number of serotonin-positive neurons in the dorsal raphe nuclei. This reduction was reversed by either estrogen or remifemin, a herbal medicine containing triterpene glycosides and phenolic substances, used for the relief of menopausal symptoms (Wang et al., 2016).

The present results also indicated a stimulatory action, as evidenced by the absence of serotonin hypophagia and the slightly decreased microdialysate levels in the OVX group. A recent study in mice has shown an inverse relationship between estrogen and serotonergic activity, as 5-HT striatal microdialysate levels were found to be lower in the high estrogen than in the low estrogen phase of the ovarian cycle. Importantly, this effect was linked to inhibition of 5-HTT expression (Yang et al., 2015), 

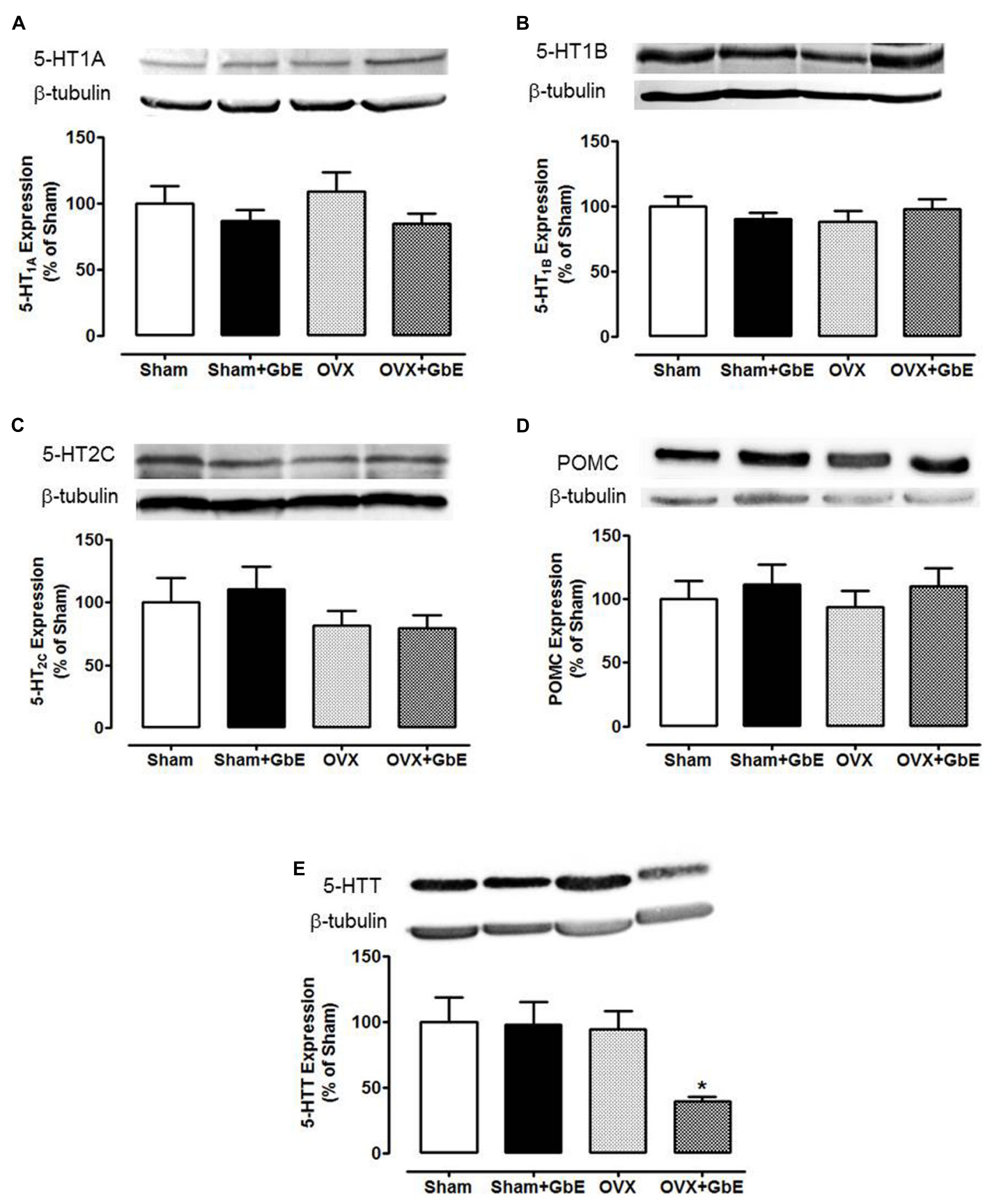

FIGURE 6 | Western blotting analysis of the hypothalamic expression of the proteins serotonin receptors $1 \mathrm{~A}, 1 \mathrm{~B}$, and $2 \mathrm{C}$, serotonin transporter (5-HTT), and POMC (A) 5- $\mathrm{HT}_{1 \mathrm{~A}}$; (B) 5-HT $1 \mathrm{~B}$; (C) 5-HT2C; (D) POMC; and (E) 5-HTT expression, in \% of Sham group expression. Sham $(n=12-13), \mathrm{Sham}+\mathrm{GbE}(n=11-12), \mathrm{OVX}$ $(n=12-14)$, and OVX $+\operatorname{GbE}(n=10-11) .{ }^{*} p<0.05$ vs. Sham.

similarly to the present observation concerning the effect of $\mathrm{GbE}$ in the OVX rats. These considerations raise the suggestion that the positive role of $\mathrm{GbE}$ on serotonergic regulation may rely on mechanisms similar to those targeted by estrogens. This agrees with the absence of GbE's effects on the Sham-OVX animals.

In human breast cancer cells, both estrogenic and antiestrogenic actions of $\mathrm{GbE}$ have been demonstrated, in a biphasic manner dependent on both estrogen and GbE concentrations. The antiestrogenic role of $\mathrm{GbE}$ has been linked to competition with estrogens for ER- $\beta$ binding, pointing GbE as a chemopreventive agent for breast cancer development, an important side effect of HRT (Oh and Chung, 2004, 2006).

In summary, ovariectomy increased body mass and adiposity and impaired the anorexigenic effect of serotonin. On the other hand, GbE reduced food intake and body adiposity, 
restored serotonin effectiveness, enhanced 5-HT levels of medial hypothalamus microdialysates and decreased 5-HTT hypothalamic levels. Our results suggest that $\mathrm{GbE}$ is a potential alternative therapy for the management of weight gain associated with menopause. More studies are necessary to understand the mechanisms involved in the beneficial role of G. biloba on the hypothalamic serotonin pathway.

\section{AUTHOR CONTRIBUTIONS}

RB, MT, and ER contributed to the study design and to the data acquisition, analysis and interpretation; drafted and revised the manuscript and provided final approval of the submitted version; responsible for all study aspects including its accuracy and integrity. IdA contributed to the data acquisition, analysis and interpretation; revised the manuscript and provided final approval of the submitted version; responsible for all study aspects including its accuracy and integrity. SC and LO contributed to the data analysis and interpretation; revised the manuscript and provided final approval of the submitted version; responsible for all study aspects including its accuracy and integrity.

\section{REFERENCES}

Ahlemeyer, B., and Krieglstein, J. (2003). Neuroprotective effects of Ginkgo biloba extract. Cell Mol. Life Sci. 60, 1779-1792. doi: 10.1007/s00018-003-3080-1

Al-Safi, Z. A., and Santoro, N. (2014). Menopausal hormone therapy and menopausal symptoms. Fertil. Steril. 101, 905-915. doi: 10.1016/j.fertnstert. 2014.02.032

Asarian, L., and Geary, N. (2013). Sex differences in the physiology of eating. Am. J. Physiol. Regul. Integr. Comp. Physiol. 305, R1215-R1267. doi: 10.1152/ajpregu. 00446.2012

Baker, J. H., and Runfola, C. D. (2016). Eating disorders in midlife women: a perimenopausal eating disorder? Maturitas 85, 112-116. doi: 10.1016/j. maturitas.2015.12.017

Banin, R. M., Hirata, B. K., Andrade, I. S., Zemdegs, J. C., Clemente, A. P., Dornellas, A. P., et al. (2014). Beneficial effects of Ginkgo biloba extract on insulin signaling cascade, dyslipidemia, and body adiposity of dietinduced obese rats. Braz. J. Med. Biol. Res. 47, 780-788. doi: 10.1590/1414$431 X 20142983$

Barth, C., Villringer, A., and Sacher, J. (2015). Sex hormones affect neurotransmitters and shape the adult female brain during hormonal transition periods. Front. Neurosci. 9:37. doi: 10.3389/fnins.2015. 00037

Bethea, C. L., Kohama, S. G., Reddy, A. P., and Urbanski, H. F. (2016). Ovarian steroids regulate gene expression in the dorsal raphe of old female macaques. Neurobiol. Aging 37, 179-191. doi: 10.1016/j.neurobiolaging.2015. 10.004

Bethea, C. L., Lu, N. Z., Gundlah, C., and Streicher, J. M. (2002). Diverse actions of ovarian steroids in the serotonin neural system. Front. Neuroendocrinol. 23, 41-100. doi: 10.1006/frne.2001.0225

Bolaños-Jiménez, F., Manhães de Castro, R., Sarhan, H., Prudhomme, N., Drieu, K., and Fillion, G. (1995). Stress-induced 5-HT1A receptor desensitization: protective effects of Ginkgo biloba extract (EGb 761). Fundam. Clin. Pharmacol. 9, 169-174. doi: 10.1111/j.1472-8206.1995.tb00277.x

Butera, P. C. (2010). Estradiol and the control of food intake. Physiol. Behav. 99, 175-180. doi: 10.1016/j.physbeh.2009.06.010

Chojnacki, C., Walecka-Kapica, E., Klupinska, G., Pawlowicz, M., Blonska, A., and Chojnacki, J. (2015). Effects of fluoxetine and melatonin on mood, sleep quality and body mass index in postmenopausal women. J. Physiol. Pharmacol. 66, $665-671$.

\section{FUNDING}

This research was supported by grants from the Brazilian agencies: Coordination for the Improvement of Higher Education Personnel (CAPES, Brazil), National Council for Scientific and Technological Development (CNPq, Brazil, process 453924/2014-0), and São Paulo Research Foundation (FAPESP, Brazil, processes 2012/03172-4 and 2014/18435-6).

\section{ACKNOWLEDGMENTS}

The authors gratefully acknowledge the valuable support given by Meira Maria Forcelini Machado, Jéssica de Souza Figueiredo, Mauro Cardoso Pereira, Valter Tadeu Boldarine, Débora Estadella, and Gianni Santos.

\section{SUPPLEMENTARY MATERIAL}

The Supplementary Material for this article can be found online at: http://journal.frontiersin.org/article/10.3389/fphar. 2017.00605/full\#supplementary-material

Clement, Y. N., Onakpoya, I., Hung, S. K., and Ernst, E. (2011). Effects of herbal and dietary supplements on cognition in menopause: a systematic review. Maturitas 68, 256-263. doi: 10.1016/j.maturitas.2010.12.005

Dalal, P. K., and Agarwal, M. (2015). Postmenopausal syndrome. Indian J. Psychiatry 57, S222-S232. doi: 10.4103/0019-5545.161483

de Sá, R. D., Crisma, A. R., Cruz, M. M., Martins, A. R., Mais, L. N., do Amaral, C. L., et al. (2016). Fish oil prevents changes induced by a high-fat diet on metabolism and adipokine secretion in mice subcutaneous and visceral adipocytes. J. Physiol. 594, 6301-6317. doi: 10.1113/JP272541

Diamond, B. J., and Bailey, M. R. (2013). Ginkgo biloba: indications, mechanisms, and safety. Psychiatr. Clin. North Am. 36, 73-83. doi: 10.1016/j.psc.2012.12.006

Eckel, L. A. (2011). The ovarian hormone estradiol plays a crucial role in the control of food intake in females. Physiol. Behav. 104, 517-524. doi: 10.1016/j.physbeh. 2011.04.014

Fehske, C. J., Leuner, K., and Müller, W. E. (2009). Ginkgo biloba extract (EGbE761) influences monoaminergic neurotransmission via inhibition of NE uptake, but not MAO activity after chronic treatment. Pharmacol. Res. 60, 68-73. doi: $10.1016 /$ j.phrs.2009.02.012

Ferreira, J. A., Foley, A. M., and Brown, M. (2012). Sex hormones differentially influence voluntary running activity, food intake and body weight in aging female and male rats. Eur. J. Appl. Physiol. 112, 3007-3018. doi: 10.1007/s00421011-2271-y

Grochans, E., Jurczak, A., Szkup, M., Samochowiec, A., Włoszczak-Szubzda, A., Karakiewicz, B., et al. (2014). Evaluation of the relationship between 5HTT and MAO gene polymorphisms, mood and level of anxiety among postmenopausal women. Int. J. Environ. Res. Public Health 12, 268-281. doi: 10.3390/ijerph120100268

Guimarães, R. B., Telles, M. M., Coelho, V. B., Mori, R. C., Nascimento, C. M., and Ribeiro, E. B. (2002). Adrenalectomy abolishes the food-induced hypothalamic serotonin release in both normal and monosodium glutamate-obese rats. Brain Res. Bull. 58, 363-369. doi: 10.1016/S0361-9230(02)00799-2

Hao, K., Gong, P., Sun, S. Q., Hao, H. P., Wang, G. J., Dai, Y., et al. (2011). Beneficial estrogen-like effects of ginsenoside Rb1, an active component of Panax ginseng, on neural 5-HT disposition and behavioral tasks in ovariectomized mice. Eur. J. Pharmacol. 659, 15-25. doi: 10.1016/j.ejphar.2011.03.005

Hirata, B. K., Banin, R. M., Dornellas, A. P., de Andrade, I. S., Zemdegs, J. C., Caperuto, L. C., et al. (2015). Ginkgo biloba extract improves insulin signaling and attenuates inflammation in retroperitoneal adipose tissue depot of obese rats. Mediators Inflamm. 2015:419106. doi: 10.1155/2015/419106 
Hiroi, R., and Neumaier, J. F. (2009). Estrogen decreases 5-HT1B autoreceptor mRNA in selective subregion of rat dorsal raphe nucleus: inverse association between gene expression and anxiety behavior in the open field. Neuroscience 158, 456-464. doi: 10.1016/j.neuroscience.2008.10.016

Huang, X. F., Huang, X., Han, M., Chen, F., Storlien, L., and Lawrence, A. J. (2004). 5-HT2A/2C receptor and 5-HT transporter densities in mice prone or resistant to chronic high-fat diet-induced obesity: a quantitative autoradiography study. Brain Res. 1018, 227-235. doi: 10.1016/j.brainres.2004.05.093

Huguet, F., Drieu, K., and Piriou, A. (1994). Decreased cerebral 5-HT1A receptors during ageing: reversal by Ginkgo biloba extract (EGb 761). J. Pharm. Pharmacol. 46, 316-318. doi: 10.1111/j.2042-7158.1994.tb03802.x

Ibrahim, B. A., Alenazi, F. S., and Briski, K. P. (2015). Energy status determines hindbrain signal transduction pathway transcriptional reactivity to AMPK in the estradiol-treated ovariectomized female rat. Neuroscience 22, 888-899. doi: 10.1016/j.neuroscience.2014.10.068

Jenabi, E., Shobeiri, F., Hazavehei, S. M. M., and Roshanaei, G. (2015). Assessment of questionnaire measuring quality of life in menopausal women: a systematic review. Oman Med. J. 30, 151-156. doi: 10.5001/omj.2015.34

Kam, I. W., Dennehy, C. E., and Tsourounis, C. (2002). Dietary supplement use among menopausal women attending a San Francisco health conference. Menopause 9, 72-78. doi: 10.1097/00042192-200201000-00011

Leibowitz, S. F., and Alexander, J. T. (1998). Hypothalamic serotonin in control of eating behavior, meal size, and body weight. Biol. Psychiatry 44, 851-864. doi: 10.1016/S0006-3223(98)00186-3

MacLean, P. S., Giles, E. D., Johnson, G. C., McDaniel, S. M., Fleming-Elder, B. K., Gilman, K. A., et al. (2010). A surprising link between the energetics of ovariectomy-induced weight gain and mammary tumor progression in obese rats. Obesity 18, 696-703. doi: 10.1038/oby.2009.307

Montes, P., Ruiz-Sanchez, E., Rojas, C., and Rojas, P. (2015). Ginkgo biloba extract 761: a review of basic studies and potential clinical use in psychiatric disorders. CNS Neurol. Disord. Drug Targets 14, 132-149. doi: 10.2174/ 1871527314666150202151440

Mori, R. C., Guimarães, R. B., Nascimento, C. M., and Ribeiro, E. B. (1999). Lateral hypothalamic serotonergic responsiveness to food intake in rat obesity as measured by microdialysis. Can. J. Physiol. Pharmacol. 77, 286-292. doi: 10.1139/y99-024

Oh, S. M., and Chung, K. H. (2004). Estrogenic activities of Ginkgo biloba extracts. Life Sci. 74, 1325-1335. doi: 10.1016/j.lfs.2003.06.045

Oh, S. M., and Chung, K. H. (2006). Antiestrogenic activities of Ginkgo biloba extracts. J. Steroid Biochem. Mol. Biol. 100, 167-176. doi: 10.1016/j.jsbmb.2006. 04.007

Olivier, B., and van Oorschot, R. (2005). 5-HT1B receptors and aggression: a review. Eur. J. Pharmacol. 526, 207-217. doi: 10.1016/j.ejphar.2005.09.066

Pines, A., and Shapiro, S. (2015). Long-term menopausal hormone therapy and health consequences - how to choose sides? Climacteric 18, 441-443. doi: 10.3109/13697137.2015.1041756

Pôrto, L. C., Sardinha, F. L., Telles, M. M., Guimarães, R. B., Albuquerque, K. T., Andrade, I. S., et al. (2009). Impairment of the serotonergic control of feeding in adult female rats exposed to intra-uterine malnutrition. Br. J. Nutr. 101, 1255-1261. doi: 10.1017/S0007114508061503

Pratt, W. E., Clissold, K. A., Lin, P., Cain, A. E., Ciesinski, A. F., Hopkins, T. R., et al. (2016). A systematic investigation of the differential roles for ventral tegmentum serotonin 1- and 2-type receptors on food intake in the rat. Brain Res. 1648, 54-68. doi: 10.1016/j.brainres.2016.07.016
Ramassamy, C., Christen, Y., Clostre, F., and Costentin, J. (1992). The Ginkgo biloba extract, EGb761, increases synaptosomal uptake of 5-hydroxytryptamine: in-vitro and ex-vivo studies. J. Pharm. Pharmacol. 44, 943-945. doi: 10.1111/j.2042-7158.1992.tb03244.x

Rivera, H. M., and Eckel, L. A. (2005). The anorexic effect of fenfluramine is increased by estradiol treatment in ovariectomized rats. Physiol. Behav. 86, 331-337. doi: 10.1016/j.physbeh.2005.08.004

Sloley, B. D., Urichuk, L. J., Morley, P., Durkin, J., Shan, J. J., Pang, P. K., et al. (2000). Identification of kaempferol as a monoamine oxidase inhibitor and potential Neuroprotectant in extracts of Ginkgo biloba leaves. J. Pharm. Pharmacol. 52, 451-459. doi: 10.1211/0022357001774075

Stachowiak, G., Pertyński, T., and Pertyńska-Marczewska, M. (2015). Metabolic disorders in menopause. Prz. Menopauzalny 14, 59-64. doi: 10.5114/pm.2015. 50000

Stanquini, L. A., Resstel, L. B., Corrêa, F. M., Joca, S. R., and Scopinho, A. A. (2015). Prelimbic cortex 5-HT1A and 5-HT2C receptors are involved in the hypophagic effects caused by fluoxetine in fasted rats. Pharmacol. Biochem. Behav. 136, 31-38. doi: 10.1016/j.pbb.2015.06.011

Telles, M. M., Guimarães, R. B., and Ribeiro, E. B. (2003). Effect of leptin on the acute feeding-induced hypothalamic serotonergic stimulation in normal rats. Regul. Pept. 115, 11-18. doi: 10.1016/S0167-0115(03)00129-0

Wang, W., Cui, G., Jin, B., Wang, K., Chen, X., Sun, Y., et al. (2016). Estradiol Valerate and Remifemin ameliorate ovariectomy-induced decrease in a serotonin dorsal raphe-preoptic hypothalamus pathway in rats. Ann. Anat. 208, 31-39. doi: 10.1016/j.aanat.2016.08.001

Woods, S. C. (2013). Metabolic signals and food intake. Forty years of progress. Appetite 71, 440-444. doi: 10.1016/j.appet.2012.08.016

Yang, H., Sampson, M. M., Senturk, D., and Andrews, A. M. (2015). Sex- and SERT-mediated differences in stimulated serotonin revealed by fast microdialysis. ACS Chem. Neurosci. 6, 1487-1501. doi: 10.1021/acschemneuro. 5 b00132

Yoshitake, T., Yoshitake, S., and Kehr, J. (2010). The Ginkgo biloba extract EGb 761(R) and its main constituent flavonoids and ginkgolides increase extracellular dopamine levels in the rat prefrontal cortex. Br. J. Pharmacol. 159, 659-668. doi: 10.1111/j.1476-5381.2009.00580.x

Yu, Z., Geary, N., and Corwin, R. L. (2011). Individual effects of estradiol and progesterone on food intake and body weight in ovariectomized binge rats. Physiol. Behav. 104, 687-693. doi: 10.1016/j.physbeh.2011.07.017

Zhu, Z., Liu, X., Senthil Kumar, S. P., Zhang, J., and Shi, H. (2013). Central expression and anorexic effect of brain-derived neurotrophic factor are regulated by circulating estradiol levels. Horm. Behav. 63, 533-542. doi: 10.1016/j.yhbeh.2013.01.009

Conflict of Interest Statement: The authors declare that the research was conducted in the absence of any commercial or financial relationships that could be construed as a potential conflict of interest.

Copyright (C) 2017 Banin, de Andrade, Cerutti, Oyama, Telles and Ribeiro. This is an open-access article distributed under the terms of the Creative Commons Attribution License (CC BY). The use, distribution or reproduction in other forums is permitted, provided the original author(s) or licensor are credited and that the original publication in this journal is cited, in accordance with accepted academic practice. No use, distribution or reproduction is permitted which does not comply with these terms. 